\title{
Capitalismo verde e justiça distributiva no descarte de resíduos eletroeletrônicos
}

\author{
Green capitalism and distributive justice in the disposal of electro-eletronic residues \\ Capitalismo verde y justicia distributiva en la eliminación de residuos electrónicos
}

Recebido: 26/02/2021 | Revisado: 04/03/2021 | Aceito: 19/03/2021 | Publicado: 25/03/2021

\author{
Diego Henrique Damasceno Coêlho \\ ORCID: https://orcid.org/0000-0002-1553-0958 \\ Universidade Federal Fluminense, Brasil \\ E-mail: diegocoelho.contato@gmail.com \\ Camila Braga Corrêa \\ ORCID: https://orcid.org/0000-0002-4335-6205 \\ Centro Universitário UNIFACIG, Brasil \\ E-mail: camilabragacorrea@gmail.com \\ Flávio Carvalho Ribeiro \\ ORCID: https://orcid.org/0000-0002-3853-5583 \\ Universidade Federal Fluminense, Brasil \\ E-mail: flavioribeiro10@gmail.com \\ Claude Adélia Moema Jeanne Cohen \\ ORCID: https://orcid.org/0000-0002-2359-8717 \\ Universidade Federal Fluminense \\ E-mail: claudecohen@id.uff.br
}

\begin{abstract}
Resumo
Na manufatura de aparelhos eletroeletrônicos, vários matérias são empregados, especialmente metais e plásticos, de decomposição delongada e altos índices de impactos negativos para o meio ambiente. O presente artigo tem por escopo examinar, em ótica interdisciplinar, o capitalismo verde como mecanismo de gestão no descarte de resíduos eletroeletrônicos, perfazendo uma análise crítica quanto às práticas anticapitalistas e não consumistas como métodos redutores da poluição por obsolescência programada, bem como as legislações brasileiras e os esforços de organizações internacionais voltados para a redução de impactos ecológicos poluidores, ligados à produção industrial, o consumo e má gestão do lixo, face a interesses políticos, econômicos e sociais. No intuito de promover uma abordagem contextualizada, utilizou-se uma metodologia quanti-qualitativa, de caráter investigativo e interpretativo, que compreende a revisão bibliográfica, através de um viés crítico e comparativo, examinando também informações quantitativas nas produções mais recentes, num diálogo entre árvores científicas, tendo como pano de fundo a justiça distributiva na teoria da justiça como equidade, de John Rawls (1997) e revisitada por Ronald Dworkin (2006), como uma equidade social, aplicada à promoção do direito à cidade, proposta por Henry Lefebvre (2001). Ao final, a pesquisa concluiu que os diálogos globais, econômicos e sociais, ainda são incipientes, no tocante ao descarte de resíduos eletroeletrônicos, ainda que a reciclagem de componentes e peças dessa linha de aparelhos possa ser recolhida e reciclada de maneira mais organizada, posto que a tragédia anunciada poderia ter os seus impactos mitigados, por meio da aplicação de paradigmas da justiça distributiva, desde a formação do pensamento e das técnicas de produção industrial.
\end{abstract}

Palavras-chave: Capitalismo verde; Resíduos eletroeletrônicos; Justiça distributiva; Cidadania; Direito à cidade.

\begin{abstract}
In the manufacture of electro-electronic devices, various materials are used, especially metals and plastics, with longterm decomposition and high levels of negative impacts on the environment. The aim of this article is to examine, from an interdisciplinary perspective, green capitalism as a management mechanism for the disposal of electronic waste, making a critical analysis of anti-capitalist and non-consumerist practices as methods that reduce policy by programmed obsolescence, as well as Brazilian legislation. and the efforts of international organizations aimed at reducing polluting ecological impacts, linked to industrial production, consumption and poor waste management, in the face of political, economic and social interests. In order to promote a contextualized approach, using an quanti-qualitative methodology, of an investigative and interpretative character, which includes a bibliographic review, through a critical and comparative bias, also examining quantitative information in the most recent productions, in a dialogue between scientific trees, against the background of distributive justice in the theory of justice as equity, by John Rawls (1997) and revisited by Ronald Dworkin (2006), as a social equity, applied to the promotion of the right to the city, proposed by Henry Lefebvre (2001) In the end, a survey considered that the global, social and social dialogues are still incipient, not regarding the disposal of electronic waste, although the recycling of components and parts of the appliance line can
\end{abstract}


be collected and recycled in a more organized way, given that the announced tragedy could have its acts mitigated, through the application of paradigms of justice from the formation of industrial production thinking and techniques.

Keywords: Green capitalism; Residuals of electrical and electronic goods; Distributive justice; Citizenship; Right to the city.

\section{Resumen}

En la fabricación de dispositivos electroelectrónicos se utilizan diversos materiales, especialmente metales y plásticos, con descomposición a largo plazo y altos niveles de impactos negativos sobre el medio ambiente. El objetivo de este artículo es examinar, desde una perspectiva interdisciplinaria, el capitalismo verde como mecanismo de gestión para la disposición de residuos electrónicos, haciendo un análisis crítico de las prácticas anticapitalistas y no consumistas como métodos que reducen las políticas por obsolescencia programada, como así como la legislación brasileña y los esfuerzos de organismos internacionales encaminados a reducir los impactos ecológicos contaminantes, vinculados a la producción industrial, el consumo y la mala gestión de residuos, frente a intereses políticos, económicos y sociales. Con el fin de promover un enfoque contextualizado, utilizando una metodología cuanti-cualitativa, de carácter investigativo e interpretativo, que incluya una revisión bibliográfica, mediante un sesgo crítico y comparativo, examinando también información cuantitativa en las producciones más recientes, en un diálogo entre árboles científicos. , en el contexto de la justicia distributiva en la teoría de la justicia como equidad, de John Rawls (1997) y revisada por Ronald Dworkin (2006), como equidad social, aplicada a la promoción del derecho a la ciudad, propuesta por Henry Lefebvre (2001) Al final, una encuesta consideró que los diálogos globales, sociales y sociales son aún incipientes, no en lo que respecta a la eliminación de residuos electrónicos, aunque el reciclaje de componentes y partes de la línea de electrodomésticos se puede recolectar y reciclar de una manera más organizada. manera, dado que la tragedia anunciada podría tener sus actos mitigados, mediante la aplicación de paradigmas de justicia a partir de la formación del pensamiento y las técnicas de producción industrial.

Palabras clave: Capitalismo verde; Desechos electrónicos; Justicia distributiva; Ciudadanía; Derecho a la ciudad.

\section{Introdução}

O extremo final do consumo é consubstanciado pelo descarte de resíduos, dado ao fim da vida útil dos bens produzidos a mercados aquecidos mundialmente e nos mais variados setores da indústria, ensejando responsabilidades ambientais (Benjamin, 1998). Com a expansão da tecnologia, os resíduos eletroeletrônicos também aumentaram vertiginosamente de volume, fato este decorrido da obsolescência programada, como estratégia de mercado para criação de demanda contínua (Lena \& Nascimento, 2012).

A responsabilidade no pós-consumo aduz à análise acerca dos danos presentes, futuros e da responsabilização de consumidores e produtores (Ralws, 1997), num conflito socioambiental que permeia interesses de grandes corporações, ainda pouco balizadas legalmente quanto ao destino final de seus produtos (Nalini, 2010), uma vez que são isentas de mecanismos jurídico-políticos de planejamento e gestão e, tampouco, de instituições de Direito Internacional, órgãos fiscalizatórios e iniciativa popular (Benjamin, 1998), com o condão de organizar a gestão do descarte, principalmente quando este se dá em comunidades economicamente anêmicas e, por conseguinte, em aumentada vulnerabilidade.

Dessa forma, o presente estudo propõe um debate, de modo a promover uma análise dos mecanismos e construtos jurídicos voltados para as responsabilidades imersas no manancial de deveres e desdobramentos das políticas de desenvolvimento econômico e do fomento ao consumo, sob o prisma da utilização do capitalismo verde como incentivo ao planejamento de redução de danos ambientais sistêmicos a territórios urbanos e rurais, principalmente realizados no intuito de diminuir ou impedir a formação de uma lixeira nacional, também considerando os efeitos transfronteiriços e transnacionais que podem ser causados pelos resíduos, destacadamente, os eletroeletrônicos.

Outrossim, pretende-se analisar a sociedade de consumo face à degradação ambiental, a qual vem fragilizando a sobrevivência de espécies animais humanas e não-humanas e, por vezes, endêmicas a determinadas espaços geográficos, pois comprometem a qualidade de vida geral, partindo inicialmente de uma escala fixada sob o comportamento individual, passando para um patamar transnacional de produção de resíduos, vindos do exterior para o Brasil. 


\section{Metodologia Empregada}

O trabalho emprega uma metodologia qualitativa (Pereira et al, 2018), voltada para a revisão bibliográfica de livros, artigos científicos, normas e produções acadêmicas interdisciplinares, em análise investigativa, em perspectiva mesclada à revisão de dados quantitativos e marcadores apresentados em documentos e pesquisas afetas ao tema, buscando produzir um diálogo atualizado entre os limites da coerção legal e os mecanismos alternativos de preservação ambiental. Pata tanto, buscouse compreender as dimensões sobre a justiça distributiva, conforme proposta por John Rawls (1997), a fim de perfazer uma base teórica e conceitual capaz de nortear a análise proposto em relação ao descarte de resíduos eletroeletrônicos.

Sob o ponto de vista interdisciplinar, o trabalho mesclou conceitos e teorias advindas das árvores científicas do Direito, da Economia, da Sociologia e das Ciências Políticas, visto que o problema pode ser compreendido tanto como uma questão cultural, quando do sistema capitalista, o que guarda profunda relação também com os campos epistemológicos da Economia Política, com majorado enfoque aos fenômenos atrelados ao capitalismo verde dentro do direito das cidades, à cidadania, ao acesso a um ambiente saudável e à retenção dos abusos capitalistas, a partir da análise de uma possível aplicação prática da justiça distributiva (Rawls, 1997), como uma das formas de engajamento civil e política, voltado para a solução do problema analisado.

\section{A Realização da Produção sob a Perspectiva do Capitalismo Verde}

$\mathrm{O}$ desempenho de uma atividade econômica tende a provocar variados impactos ambientais, especialmente aqueles decorrentes das buscas desmedidas do crescimento econômico, condicionadas por uma mentalidade cujos objetivos orbitam no aumento contínuo das margens de lucros (Rawls, 1997). Tais fatores reiteram formas de exploração desenfreadas e irresponsáveis no planeta, tornando mais acentuados os impactos perniciosos da degradação ambiental (Nalini, 2010).

Nessa conjuntura, mesmo sob um prisma econômico, é possível perceber que não mais é possível prosseguir sem a preocupação e a responsabilidade com as questões ambientais. Emerge, pois, o grande desafio de buscar conciliar o desenvolvimento econômico e a preservação do meio ambiente. Conforme ensina John Rawls (1997), a consciência de que os recursos naturais são finitos colide com a utilização descontrolada do planeta, comprometendo a qualidade de vida das gerações atuais e a sobrevivência digna das gerações futuras.

Tais premissas passaram a impulsionar o surgimento de ideias, cuja difusão voltada à proteção do meio ambiente deu origem a documentos legais e políticos. (Retondar, 2007), cujos estudos científicos, a exemplo, produziram os resultados apresentados em 1983, pela Comissão Mundial sobre o Meio Ambiente e Desenvolvimento, chefiada pela então primeiraministra da Noruega, Brundtland, a qual teve o seu nome utilizado como antroponímico para o resumo conhecido como "Relatório Brundtland", também intitulado formalmente como "Nosso Futuro Comum" (Comissão Mundial sobre Desenvolvimento e Meio Ambiente, 1992), apresentando a noção de desenvolvimento sustentável como aquele, "que encontra as necessidades atuais sem comprometer a habilidade das futuras gerações de atender suas próprias necessidades" (ONU-Brasil, online).

Já no final do século XX e primeiras décadas do século XXI, a sustentabilidade passou a ser analisada sob as perspectivas ambientais, sociais e econômicas, com base nas ideias de John Elkington, que cunhou o termo Triple Bottom Line (Elkington, 2001), ou Tripé da Sustentabilidade, trazendo uma concepção de que o desenvolvimento econômico sustentável deve ser ecologicamente correto e, ainda, um fator de justiça social.

Nessa perspectiva, o planejamento de um desenvolvimento econômico atrelado ao desenvolvimento humano, capazes de colaborarem para com a construção de uma sociedade mais justa e igualitária, coexistem na formação de um contexto mais adequado a ser almejado; todavia representam um grande desafio e um ideal de consubstanciação demorada. Apesar de apresentar 
algumas limitações, o modelo do Triple Bottom Line conquistou espaço, sendo reconhecido e aplicado por parte do empresariado, conforme ensinam Flores, Araújo e Tybusch, in verbis:

[...] o modelo do triple bottom line ganhou a adesão de grande parte do núcleo empresarial ao aventar a possibilidade de maiores lucros juntamente com uma política de resultados que implica maior responsabilidade ambiental. Tal modelo estimula os consumidores a se tornarem "verdes", ou seja, serem responsáveis em suas escolhas ao optarem por produtos de empresas supostamente comprometidas com a sustentabilidade" (Flores, Araújo \& Tybusch, 2013, p.791).

O desenvolvimento por parte das empresas de uma política voltada para a responsabilidade social e ambiental representa, portanto, uma boa estratégia de marketing, com foco na conquista da fidelização de grande parte de consumidores sensibilizados com as questões ambientais (Retondar, 2007),e também incentiva teorias interdisciplinares de sistemas nas empresas aderentes ao modelo Triple Bottom Line; essas empresas passaram a adotar políticas de governança e estratégias de marketing focadas na responsabilidade social e ambiental, de modo a utilizar o Capitalismo Verde como uma forma de legitimação social, conforme lê-se abaixo:

O capitalismo verde encaixou-se perfeitamente no interior das grandes empresas, porque deu a elas uma legitimação social necessária em termos mercadológicos. Assistiu-se um multiplicar de etiquetas "verdes" nos produtos, desde itens básicos de alimentação até bens duráveis, como os eletroeletrônicos e os automóveis. A crise ecológica forçou alterações na lógica de consumo, mas em grande parte sem alterar a lógica destruidora que a deu causa (Flores, Araújo \& Tybusch, 2013, p.791).

A conscientização dos consumidores tornou necessária a adequação dos produtos que a eles eram destinados, fomentando um novo mercado de consumo, voltado para a perspectiva de economia verde. Dentro desse escopo, buscou-se uma melhor eficiência e racionalização de recursos naturais, uso de energias renováveis (Lena; Nascimento, 2012), como, por exemplo, a energia eólica, o desenvolvimento de técnicas e de tecnologias que minimizem os impactos ambientais, enfim, ações que visem à sustentabilidade, agregada à preocupação com a justiça social (Flores, Araújo \& Tybusch, 2013).

Em contrapartida, a disponibilização e a oferta de produtos no mercado por empresas, sob o simples selo publicitário de adequação aos paradigmas do Capitalismo Verde, não alcançavam de maneira eficiente as abordagens da consciência ecológica e do desenvolvimento sustentável, como fatores de responsabilidade social e responsabilidade ambiental (Lena, Nascimento, 2012). Estes últimos enfoques foram então revisitados e amplamente discutidos, visando as readequações estabelecidas durante a Conferência Rio +20, na perspectiva da economia verde (Nalini, 2010).

A continuidade dos estudos e debates voltados para o aperfeiçoamento dos métodos de produção, distribuição e impactos de produtos e serviços em adequação às égides propostas pelo Capitalismo Verde tornaram-se pautas do Programa das Nações Unidas para o Meio Ambiente - PNUMA (2011), quando foi conceituada a economia verde como aquela traz melhoria no bemestar da humanidade e igualdade social, reduzindo, de forma significativa, riscos ambientais e escassez ecológica.

\section{A Sustentabilidade e a Preservação Ambiental como Imperativos Legais no Brasil}

A partir da premissa de que os problemas ambientais não orbitam apenas em torno do melhor uso de recursos naturais nas atividades econômicas, mas decorrem em grande parte do impacto causado pela ausência de gestão de seus resíduos e do lixo produzido pela sociedade consumista, torna-se perceptível o seguinte paradoxo: quando o próprio empresariado capitalista torna-se responsável por desenvolver estratégias para incentivar o consumidor a comprar mais dos seus produtos (Lena; Nascimento, 2012), face a tais bens de consumo serem oferecidos com nova roupagem, com novo estilo e programados para se tornarem obsoletos, conduzindo à nova compra (Rawls, 1997), como se tornam possíveis os incentivos ao consumo, nas medidas 
da economia "verde" que ofereçam soluções viáveis à produção, pois urgente e necessária é a redução da proporção alarmante de consumo e descarte desenfreados?

Nesse ponto, a discussão se desdobra por sobre a possibilidade de reconhecimento de uma forma de consumo que deve ser "verde", evidenciando uma necessidade de conscientização do consumidor do seu importante papel na preservação do meio ambiente e no exercício da cidadania (Elkington, 2001), principalmente quando os impactos ocorrem não apenas para o empresário produtor ou o consumidor final, mas atingem à coletividade.

Assim, a Lei no 10.257 de 2001, conhecida como "Estatuto da Cidade", apresenta em seu art. $2^{\circ}$, incisos I e II o direito às cidades sustentáveis, regulamentando as previsões já realizadas nos arts. 182 e 183 da Constituição Federal de 1988 (Brasil, 2018), sobre as políticas sociais de garantias do direito à terra urbana, à moradia, ao saneamento ambiental, à infraestrutura urbana, ao transporte e aos serviços públicos, ao trabalho e ao lazer, para as presentes e futuras gerações" (Brasil, 2001). A instituição de tais direitos é compreendida por Henri Lefebvre (2001) nas perspectivas abaixo transcritas, in verbis:

O direito à cidade se manifesta como forma superior dos direitos: direito à liberdade, à individualização na socialização, ao habitat e ao habitar. $\mathrm{O}$ direito à obra (à atividade participante) e o direito à apropriação (bem distinto do direito à propriedade) estão implicados no direito à cidade (Lefebvre, 2001, p. 32).

Neste espeque, o direito da cidade é tão relevante que sua inobservância ofende ao princípio da dignidade da pessoa humana (Flores, Araújo \& Tybusch, 2013). O acúmulo de lixo e de resíduos prejudica a qualidade de vida nas cidades, comprometendo o direito à cidade, o qual há de ser defendido com a participação e atuação consciente de seus cidadãos (Benjamin, 1998). Logo, a relevância de uma educação ambiental capaz de conscientizar a respeito das responsabilidades e implicações coletivas e difusas (Lefebvre, 2001) pode ser apresentada como um dos instrumentos eficazes para conduzir o homem no caminho da cidadania e promover transformações (Lena \& Nascimento, 2012).

A Lei no 9.795/1999 (Brasil, 1999) disciplina a Política Nacional de Educação Ambiental no Brasil e apresenta em seu art. $1^{\circ}$, o conceito de Educação Ambiental:

Entendem-se por educação ambiental os processos por meio dos quais o indivíduo e a coletividade constroem valores sociais, conhecimentos, habilidades, atitudes e competências voltadas para a conservação do meio ambiente, bem de uso comum do povo, essencial à sadia qualidade de vida e sua sustentabilidade (Brasil, 1999, on-line).

A educação ambiental é, inclusive, previsão constitucional, inserida no Artigo 225, VI, da Constituição Federal de 1988, que atribui ao Poder Público o dever de "promover a educação ambiental em todos os níveis de ensino e a conscientização pública para a preservação do meio ambiente" (Brasil, 2018).

A articulação entre o direito ambiental e o do consumidor, no ordenamento jurídico brasileiro, faz-se presente na Constituição Federal (Brasil, 2018), quando, de maneira concomitante, estimula e assegura a livre iniciativa e a livre concorrência (art. 170, VI da CF/1988), bem como impõe o dever de preservação e de defesa do meio ambiente e a defesa do consumidor (art. $5^{\circ}$, XXXII e 170, V da CF/1988), além de possuir dispositivos complementares inseridos em outros diplomas legais, tais como a Lei de Política de Recursos Hídricos (Lei 9.433/1997) e o Código Florestal (Lei 12.651/2012), possuindo maior correlação no presente estudo a Lei da Política Nacional de Resíduos Sólidos (Lei 12.305/2010), que cuida com preocupação sobre o ciclo de vida dos produtos disponíveis no mercado e a Norma Técnica da ABNT 14.071 (2018), que cuida da Avaliação do ciclo da vida.

Outrossim, reveste-se de especial relevância a previsão constitucional de dois instrumentos de defesa do meio ambiente: a ação popular prevista no inciso LXXIII, do artigo $5^{\circ}$ e a ação civil pública prevista no artigo 129, III (Brasil, 2018), que muito tem contribuído para o desenvolvimento do Direito Ambiental Brasileiro e de entendimentos jurisprudenciais (Benjamin, 1998). 
Em escala mundial, dentre os diplomas legais que cuidam do tema em análise, vale destacar a Resolução 44/228, da Assembleia Geral das Nações Unidas (1985), que cuida do manejo ambiental saudável dos resíduos pós-consumo, diante da possibilidade de ter por comprometida a qualidade do meio ambiente e, por conseguinte, a saúde do consumidor, além da Convenção de Basiléia (apud MILARÉ, 2001) que, desde 1992, ao fazer frente às exportações ilegais de resíduos perigosos tem como principais objetivos:

(I) Estabelecer obrigações com vistas a reduzir ao mínimo os movimentos transfronteiriços de resíduos perigosos, e exigir que seu manejo seja feito de maneira eficiente e ambientalmente segura;

(II) Minimizar a quantidade e a toxicidade dos resíduos gerados, garantir (depósito e recuperação) e assistir aos países em desenvolvimento na implementação de suas disposições;

(III) Proibir seu embarque para países que não tenha capacidade para eliminar resíduos perigosos de forma ambientalmente segura (Milaré, 2011, p. 1525).

Ao tratar dos resíduos, Aragão ensina que eles "estão na origem dos mais variados tipos de poluição, causando perturbações ambientais na hidrosfera, na atmosfera, na litosfera e na biosfera", ou seja, "constituem uma fonte de perigos para a vida e para a saúde, bem como para o equilíbrio dos ecossistemas" (Aragão, 2003, on-line).

Assim sendo, a atuação dos Poderes Legislativo e Executivo mediante a confecção e implantação de tais normas representa os anseios e benefícios projetados acerca da redução de poluentes e do desenvolvimento de um consumo mais consciente, utilizando componentes recicláveis (Nalini, 2010), face à indiferença e à irresponsabilidade produtivas, as quais representam incidentes causadoras da degradação ambiental na era contemporânea, desencadeadas pelo consumismo desenfreado (Benjamim, 1988).

\section{Harmonização dos Conflitos Ecológicos e Econômicos: Produção, Consumo e Descarte}

Dentro de uma esfera social, não se pode perder de vista que, ao mesmo tempo em que os Estados devem garantir a produção de normas balizadoras e fomentar o desenvolvimento de tecnologias, também precisam garantir o equilíbrio ecológico (Rawls, 1997). Portanto, na lógica mercadológica capitalista - na qual o lucro é o fim a ser alcançado - sob uma visão preponderantemente individual, a natureza privada pode se sobrepor à natureza pública, todavia, não pode solapá-la, haja vista a necessidade de se resguardar a vontade coletiva (Lefebvre,2001).

Por outro lado, dentro de uma esfera jurídica, ao se tratar dos danos ambientais, a responsabilidade deve ir além da visão clássica do dever de reparar - cujos pressupostos são o dano, o nexo de causalidade e a culpa, conforme ensina Henry Lefebvre (2001), seja porque cuida de um bem comum do povo incapaz de comportar apropriação exclusiva por ser incorpóreo, imaterial e indivisível seja porque cuida de um bem de interesse jurídico autônomo. Ademais, quanto ao nexo de causalidade, há uma cadeia de eventos antecedendo ao desfecho danoso (Benjamin, 1998). Nesse caso, é difícil indicar, dentre eles, o nexo para estabelecer onde se situa a causa real ou eficiente do dano (Pereira, 1999), o que enseja a adoção de uma teoria fundada em probabilidades, como também a análise da manifestação da extensão dos danos em momentos diversos do presente, haja vista ser necessário considerar que os avanços científicos, o progresso da tecnologia e o crescimento industrial desencadeiam um conjunto de variáveis capazes de produzir profundas consequências das atividades econômicas (extrativismo, transformação, beneficiamento, produção, consumo e descarte) sobre o meio ambiente (Rawls, 1997).

Os conflitos sociais aduzem a temáticas de abordagens complexas, multifacetadas e cientificamente interdisciplinares; todavia, partem do pressuposto comum de análise das questões evolucionistas que cuidam da adaptação do homem ao mundo natural e a impressão que nele deixa (Bauman, 2008; Lutzenberger, 2012); por vezes passível de se voltar para uma análise econômica e, noutras, para uma análise de interesses e estratégias adotadas para exercício do domínio ou justificação de 
identidades (Rawls, 1997; Dworkin, 2006). Já daí se vê que a "relação entre o plano discursivo e o plano das práticas, a cada inflexão nas representações dominantes sobre o meio, mudará, consequentemente, o poder relativo dos atores no campo das forças onde configuram-se os conflitos ambientais” (Acselrad, 2004).

Ao se revelarem, portanto, danos que afetam não somente os direitos de um indivíduo, mas os de uma coletividade e/ou que venham a se personificar nos bens socioambientais e geoeconômicos das gerações futuras, a responsabilidade deve se voltar para o futuro na proteção dos seres vivos e do sistema ecológico em si (Polakovic, 2002). Logo, torna-se perceptível o exercício de uma responsabilidade sob novos contornos e reflexões decorrentes do progresso da ciência, dos interesses públicos e sociais, da proteção da pessoa, da dignidade humana e dos interesses difusos, captando novas tipologias de danos, alguns, inclusive, imprevisíveis (Acselrad, 2004); tais como as situações de riscos ecologicamente instáveis ante os variados interesses pluridimensionais e, muitas vezes, conflitantes, mas igualmente dignos de tutela, envolvendo consumo e meio ambiente. (Pereira, 2001)

De forma aproximada, as perspectivas sociais, administrativas ou normativas, segundo a análise do tema aqui proposto, apresentam os conflitos ambientais como aqueles cuja amplitude envolva grupos sociais, regionais, étnicos e econômicos, com modos diferenciados de apropriação, uso e significação do território (Milaré, 2011), tendo origem quando pelo menos um dos grupos tem a continuidade das formas sociais de apropriação do meio que desenvolvem ameaçada por impactos indesejáveis (por exemplo: no ar, no solo e na topografia, na vegetação, na hidrografia, na paisagem natural) decorrentes do exercício das práticas de outros grupos (Nalini, 2010).

Nas perspectivas do capitalismo verde, do consumo sustentável e do descarte de resíduos eletroeletrônicos, tais conflitos podem ter dimensões individuais, transindivuais, transterritoriais e transnacionais, sendo que, independentemente do contexto em que são inseridos (Dworkin, 2006), "estabelecem a dicotomia entre a sustentabilidade ambiental do padrão de produção e consumo vigente hoje no conjunto das sociedades ocidentais frente à problemática relacionada com os direitos do consumidor $\mathrm{e}$ à cidadania em seus diferentes aspectos" (Lefebvre, 2001). Nessa linha de ideias, cumpre destacar que os danos ambientais transfronteiriços e transnacionais cuidam de temática atinente ao Direito Internacional do Ambiente (Benjamin, 1998), de caráter público ou privado, com possibilidades de as vítimas estarem em diferentes Estados e, por conta disso, submetidas a regimes jurídicos diferentes (Dworkin, 2006), os quais nem sempre são dotados de instrumentos processuais disponíveis para a tutela da referida pretensão. A complexidade deste tema passa pela existência de jurisdições distintas, mas igualmente competentes para a análise da matéria; pelo risco de as decisões nacionais serem conflitantes; pela distinção da abordagem do direito material e processual aplicável e pela frustração da execução diante das deficiências da decisão no direito interno (Araújo, 2001).

Do choque desses interesses, têm sido incorporados argumentos calcados na equidade intergeracional, na responsabilização de produtores e consumidores e no desenvolvimento sustentável, visando à proteção da natureza em si e no seu próprio fundamento (Retondar, 2007), sendo necessário o desenvolvimento de uma ecologia política com reformulações radicais; já que, para Latour (2004), até então o "conjunto mesclado não forma, felizmente, uma Ciência certa”, tampouco, é capaz de coibir abusos, desobediências à lei ou pavimentar posturas positivas de planejamento produtivo voltado para o descarte mínimo, a reciclagem e o reaproveitamento de produtos com maior durabilidade e reparação simplificada (Nalini, 2010; Milaré, 2011).

A resolução destas questões pode vir do Processo Civil Internacional, uma vez que sua finalidade é encontrar um ponto de equilíbrio, de modo a permitir que o direito interno seja soberano, mas também capaz de regrar os fatos que extrapolam os limites territoriais do Estado, conforme assenta Perlingeiro (2014) e, assim sendo, o foco se volta para o comportamento do indivíduo em si e da sua compreensão como ator de desenvolvimento para um consumo sustentável ou menos agressivo quanto aos malefícios que vêm causando ao meio ambiente (Elkington, 2001; Nalini, 2010). 
Para John Rawls (1997), o que se deve buscar é uma harmonia de objetivos socioeconômicos e ambientais e não o crescimento por si só. Isso porque a questão fundamental deve afastar as premissas de que os produtos ou serviços devam ser produzidos para atender as necessidades e vontades dos consumidores e fixá-las diante de um contexto que leve em consideração as consequências sociais (tais como: redução dos recursos naturais; poluição; aquecimento global etc.), o que para Wilson Madeira Filho e Alba Simon (2016) é sintetizado no sentido de "a ecologização da economia não seria tão só um problema de adequação de ritmos e de escalas, mas de mudança estrutural e de elaboração de uma nova racionalidade."

\section{A Injustiça Econômica no Descarte de Resíduos Eletroeletrônicos}

O lixo eletroeletrônico, ou e-waste, Resíduos de equipamentos elétricos e eletrônicos (REEE), lixo eletrônico ou sucata eletrônica, em diferentes regiões e sob diferentes circunstâncias no mundo, são termos utilizados para referenciar os componentes de equipamentos elétricos e eletrônicos (EEE) e suas peças, que foram descartadas pelo proprietário como lixo sem a intenção de reutilização, abarcando uma ampla gama de produtos - quase todos os itens domésticos ou comerciais com circuitos ou peças que utilizam alimentação elétrica e/ou bateria.

A definição de lixo eletrônico é muito ampla e abrange, segundo a Diretiva da Comunidade Europeia 2012/19 / EU (Parlamento Europeu; Conselho da União Europeia, 2012) dez categorias de resíduos, sendo elas: Grandes eletrodomésticos, Pequenos eletrodomésticos, Equipamento informático e de telecomunicações, Equipamento de consumo, Equipamento de iluminação, Ferramentas elétricas e eletrônicas, Brinquedos, equipamento de lazer e esportes, Dispositivos médicos, Instrumentos de monitoramento e controle e, Dispensadores automáticos.

O relatório The Global E-waste Monitor - 2017, das Nações Unidas (apud Baldé et al, 2017) apontou para contaminações do solo, do ar e da água, em países da África, na China e na Índia, pelas seguintes substâncias provenientes dos resíduos eletroeletrônicos: (I) dioxinas aerotransportadas; (II) substâncias cancerígenas em viveiros de patos e arrozais, excedendo os padrões internacionais para áreas agrícolas; (III) altos níveis de cádmio, cobre, níquel e chumbo em plantações, acima dos padrões internacionais; (IV) metais pesados encontrados no pó da estrada. Um estudo separado no depósito de lixo eletrônico de Agbogbloshie, no Gana, encontrou presença de níveis de chumbo muito altos: 18.125 ppm no solo. O padrão da EPA dos EUA para chumbo no solo em áreas de lazer é de 400 ppm e 1200 ppm para áreas de não lazer. Os trabalhadores da sucata no depósito de lixo eletrônico de Agbogbloshie queimam regularmente componentes eletrônicos e fios de chicotes para recuperação de cobre, liberando produtos químicos tóxicos como chumbo, dioxinas e furanos no meio ambiente.

Segundo o relatório do Programa das Nações Unidas para o Meio Ambiente (PNUMA) - Caminhos para o Desenvolvimento Sustentável e a Erradicação da Pobreza (PNUMA, 2011), estima-se que 50 milhões de toneladas de lixo eletrônico sejam produzidas a cada ano. Os EUA descartam 30 milhões de computadores por ano e 100 milhões de telefones são descartados na Europa a cada ano (PNUMA, 2011). A Agência de Proteção Ambiental dos EUA estima que apenas 15\% a 20\% do lixo eletrônico é reciclado, o restante desses produtos eletrônicos vai diretamente para aterros e incineradores (Baldé $e t$ al, 2017).

Em 2011, o PNUMA apontou a quantidade de lixo eletrônico mundial descartado a cada ano em 50 milhões de toneladas, prevendo que a quantidade de lixo eletrônico produzido - incluindo telefones celulares e computadores - pode aumentar em até 500\% na próxima década em alguns países, como a Índia, a China, Gana e países do Golfo da Guiné, que segundo o relatório The Global E-waste Monitor - 2017 (Baldé et al, 2017), junto com países da América Latina e demais países africanos, são os principais destinos dos REEE's descartados nos Estados Unidos, Canadá e países da Europa. Tais dados retratam a discrepância entre o acesso ao consumo e o descarte, apresentando a desigualdade de renda e a injustiça social sofrida por 
países, sociedade e ambientes naturais que recebem apenas os resíduos, apesar de não os consumir em seu estado inicial de disposição e oferta em mercados em que o capitalismo funciona de forma plena.

\section{Anticapitalismo, Justiça Distributiva e Sustentabilidade}

John Rawls, em 1971, publicou a obra "Uma teoria da justiça" e, como neocontratualista, criou um novo modelo de contrato social, tal como fizeram Hobbes (2003) e Locke (1973) às suas épocas. Este contrato de Rawls, dentro da interpretação kantiana da justiça como equidade (Rawls, 1997), parte da premissa de que as pessoas individualmente consideradas produzem muito menos riquezas, do que produzindo juntos.

Dentro do Capitalismo, a união de forças e ideias pavimenta o modelo globalizado da produção. A sociedade absolutamente interconectada deve, então, decidir os critérios de repartição das riquezas. Assim, Rawls (1997), procurando definir um novo paradigma decisório, idealizou que deveria haver um sistema aceito por todas as pessoas, independente de cor, gênero, instrução, etc, repartindo o "véu da ignorância"

Na obra de Rawls (1997), o princípio distributivo com base em critérios justos é nomeado como "Princípio da Diferença", o qual diverge da estrita igualdade, ou divisão matematicamente proporcional a todos, desde que as desigualdades em questão tornem os menos favorecidos na sociedade materialmente melhor equipados, do que estariam sob a estrita igualdade. O princípio da diferença apresenta dimensões variantes, tais como: (I) O é considerado relevante para a justiça distributiva (renda, riqueza, oportunidades, emprego, bem-estar, utilidade etc.); (II) A na natureza dos destinatários da distribuição (pessoas individuais, grupos de pessoas, classes de referência, etc.) e; (III) Em que base a distribuição deve ser feita (igualdade, maximização, de acordo com características individuais, de acordo com transações livres etc.).

Em sua releitura sobre os estudos de Rawls (1997), o professor Ronald Dworkin (2006) também elenca os importantes papéis das variáveis "responsabilidade" e "sorte", como fatores atrelados ao Princípio da Diferença de Rawls, como sendo uma espécie de "Igualitarismo da sorte", enfatizando os papéis morais de responsabilidade e sorte, mas distinguindo-os das afirmações sobre o merecimento (meritocracia) das pessoas pelo seu empenho pessoal, dedicação e trabalho, bem como realizar a distribuição de modo que os benefícios sejam também capazes de cobrir seus próprios encargos e despesas. Isso inclui questões de justiça distributiva no nível global e não apenas no nível nacional (justiça: internacional), justiça distributiva entre gerações (justiça: intergeracional) e a abordagem da justiça distributiva não como um conjunto de princípios, mas como uma virtude.

Para Rawls (1997) e para Dworkin (2006), a distribuição justa deve também levar em consideração o bem-estar dos indivíduos beneficiados (utilitarismo), que não acreditam apenas o mero fornecimento de bens e serviços materiais, posto que não possuem valor intrínseco, mas são valiosos apenas na medida em que aumentam o bem-estar, seja mediante sua maximização ou melhor distribuição, de forma que a busca de "padrões" específicos para definir as formas de distribuição, coadunem-se às demandas morais mais importantes de liberdade ou autopropriedade.

O socioliberalismo de Rawls (1997) foi atacado desde a direita ultraliberal representada pelo estado mínimo de Nozick (1974), até a esquerda marxista. Para Rawls (1997), cada vez que houvesse contraposição entre a liberdade e a desigualdade, haveria um choque de sistemas. Para os neoliberais e ultraliberais, as teses de Rawls (1997) enquadram-se como ideologia anticapitalista. Wolfgang Hock (1960) definiu o anticapitalismo como "o lado econômico de uma ideologia amplamente treinada dirigida contra o liberalismo democrático". Karl Marx e Friedrich Engels (1848) definiram o socialismo como anticapitalismo na esfera econômica. Ao mesmo tempo, o socialismo significa mais do que o anticapitalismo, e nem tudo o que é anticapitalista é proletário. Além do anticapitalismo socialista, há também um anticapitalismo crítico para a cultura que entende a ordem econômica liberal como uma cultura e natureza difamatória, respectivamente, um anticapitalismo da direita (Dworkin, 2006). 
A teoria socioliberal de Rawls (1997) foi posteriormente aperfeiçoada por Ronald Dworkin (2006). A releitura trouxe o conceito de "liberalismo igualitarista", através da distribuição da desigualdade (2006). Dessa forma, deveria ocorrer uma intervenção no mercado, com injeções financeiras em setores estratégicos, pois toda oferta encontra a sua demanda no mercado, conforme apregoa a Lei de Say, através das políticas que favorecem a oferta, estimulando empresários e reduzindo preços, para estimular o consumo (Bauman, 2008).

Sob tal prisma, surge a primeira premissa em relação ao Capitalismo como modelo econômico não generalizável, pois somente pode desenvolver-se em territórios em que hajam mercados consumidores economicamente viáveis (Dworkin, 2006), ou seja, locais em que as populações tenham poder aquisitivo suficiente para ingressarem no consumo e "participarem" de um modelo que é naturalmente exclusivista (Rawls, 1997).

A segunda premissa refere-se à utilização da justiça distributiva como modelo de sustentabilidade do capitalismo, a partir da intervenção do Estado em setores direcionados da economia, não só por uma questão de incapacidade individual para o trabalho devendo ser suprida pela beneficência estatal (Rawls, 1997), conforme apregoavam Marx e Engels (1848), mas também sob a ética institucional de auxílio a determinados grupamentos sociais (Dworkin, 2006). Neste ponto, o capitalismo verde surge como alternativa economicamente viável para a redução da emissão de resíduos e o fomento sustentável do mercado.

A sustentabilidade desponta como terceira premissa e, também, "ultima ratio" a fenômenos provocados pelo modelo capitalista por essência e a geração de abismos sociais (Dworkin, 2006) por consequência, na tentativa de promover os mecanismos jurídicos e econômicos de proteção ambiental, enquanto harmoniza direitos à cidadania e às cidades, com vistas a garantir o acesso aos espaços com bem-estar coletivo, limpeza urbana, saneamento básico e segurança pública, bem como promovendo o descarte consciente de resíduos, de modo a avalizar o ingresso num patamar civilizatório mínimo a todos (Benjamin, 1998; Nalini, 2010). A sustentabilidade também ataca diretamente a obsolescência programada, de cunho estritamente capitalista, pois amparada em tecnologias de reciclagem e maior durabilidade dos produtos, é um óbice para que os mercados programem a criação de suas próprias demandas e perpetuem os ciclos de vida útil e necessidade de substituição contínua, principalmente no tocante a bens, produtos e serviços eletroeletrônicos.

\section{A Crise Econômica de 2008, a Comprovação Anticapitalista e as Novas Formas de Planejar a}

\section{Economia}

A desigualdade se tornou um dos vieses de estudo em Economia, tendo vista que capitalismo não pode subsistir, quando houver uma desigualdade financeira demasiadamente grande (Rawls, 19997). Quando uma parcela da população se torna demasiadamente pobre, é impossível que haja mercado consumidor capaz de abarcar o sistema capitalista, dado também através de uma revolução industrial local (Dworkin, 2006; Bauman, 2008).

A crise econômica e financeira iniciada em 2008 demonstrou o quão frágeis são as bases de sustentação do capitalismo e como os cidadãos estão impotentes e desvalidos frente ao poder do capital (Nalini, 2010). A antiga crença de evolução social através do progresso tecnológico e do consumo material contínuo causou um colapso global, pois tantos desequilíbrios também evocam a série de injustiças traduzidas no campo ambiental (Latouche, 2012), na exploração da mão de obra, no desemprego e no aumento das desigualdades, na miséria, fome, poluição, contaminação do lençol freático por elementos tóxicos, dentre outros.

A crença num futuro sempre melhor foi continuamente derrogada ao longo das décadas do século XX (Rawls, 1997). A partir de então, os debates voltaram-se para a localização de outras formas de se pensar as economias, alterando as formas de produzir, consumir e distribuir (Dworkin, 2006). A demanda também consiste nos anseios de pequenos e médios empresários, os quais realizam as funções de distribuição de produtos, mercadorias e serviços, e não mais desejam estar totalmente vinculados a outras empresas de grande porte, sem qualquer poder diretivo em seu destino (Benjamin; Marques; Bessa, 2017). 
Quase todas as mudanças, sejam elas tributárias, industriais, educacionais, sanitárias, etc., têm efeitos distributivos. Como resultado, toda sociedade tem uma distribuição diferente a qualquer momento, que pode ser mensurada por indicadores cada vez abrangentes, tendo em vista novas tecnologias computacionais e o uso de Big Data, por exemplo. Assim, a ecologia crítica, a sustentabilidade, o anticapitalismo, o socioambientalismo e a justiça distributiva são ideologias interconectadas e capazes de substituir a competição pela cooperação, mediante posturas que funcionem tanto para o individual quanto para o coletivo, diminuindo o conceito de vida através da linearidade social, como um "script" a ser seguido à sombra de fórmulas de pensamento único, padronizações e os determinismos - os quais eliminam toda a potencialidade criativa e retardam o amadurecimento das sociedades e a consciência de responsabilidade coletiva em relação ao consumo e os ambientes, a médio e longo prazos. Segundo Léna e Nascimento:

A urgência ambiental e a ineficácia dos processos de desenvolvimento sustentável provocaram dois tipos de reação e propostas: uma é a "economia verde" (ou "capitalismo verde"), que aposta na tecnologia (ecoeficiência, "fazer mais com menos" etc.) para voltar a criar riqueza, crescimento e empregos (isto é, restaurar as taxas de lucro e a acumulação); outra é a saída do sistema econômico atual, do seu imaginário e dos seus valores (de forma radical ou mais reformista, e com período variável de transição). Nessa segunda família, encontramos, em particular, o movimento a favor do decrescimento e do ecossocialismo (Léna, Nascimento, 2012, p. 09).

Nesse prisma teórico, é perceptível que a viabilidade do mercado está atrelada ao consumo por parte dos indivíduos, no início do caminho (Nozick, 1974; Dworkin, 2006). Ao final, surge a equidade como paradigma ético de enfrentamento, no tocante ao descarte do considerado "lixo eletroeletrônico", cuja responsabilização é pouco discutida, mas produz impactos ambientais profundos e duradouros, já sentidos atualmente e certamente encarados também por gerações futuras (Benjamin; Marques; Bessa, 2017).

As lutas anticapitalistas, o direito à cidade e o capitalismo verde são formas de pensar e aplicar a justiça distributiva e a justiça como equidade, através dos planejamentos industriais e de mercado, a médio e longo prazo (Latouche, 2012), aumentando a durabilidade de produtos eletroeletrônicos, organizando suas formas de descarte, coleta e reciclagem, de modo a impedir o descarte internacional em territórios, quer marítimos, quer urbanos ou rurais, principalmente nas comunidades mais pobres e com menos acesso a direitos. Nessa ótica, a globalização também deve ser racionalizada para servir como sistema inclusivo, na construção da distribuição justa.

\section{O Consumismo e as Consequências do Descarte}

Segundo Bauman (2008), a lógica na sociedade de consumo é alimentar a insatisfação perpétua dos consumidores, o que é alcançado quando os produtos antes almejados se desvalorizam e se depreciam após a sua aquisição. Sem a repetida frustração dos desejos, a demanda de consumo se esgotaria logo e a economia voltada para o consumidor não teria do que se alimentar. Referido posicionamento, para os economistas, fez tanto sentido que a riqueza de uma economia e/ou nação é medida pelo lixo que ela descarta, mediante análise do PIB (produto interno bruto). Ainda nas palavras de Zygmunt Bauman:

A economia consumista se alimenta do movimento das mercadorias e é considerada em alta quando o dinheiro mais muda de mãos; e sempre que isso acontece, alguns produtos de consumo estão viajando para o depósito de lixo. Numa sociedade de consumidores, de maneira correspondente, a busca da felicidade - o propósito mais invocado e usado como isca nas campanhas de marketing destinadas a reforçar a disposição dos consumidores para se separarem de seu dinheiro (ganho ou que se espera ganhar) - tende a ser redirecionada do fazer coisas ou de sua apropriação para sua remoção - exatamente do que se precisa para fazer crescer o PIB (Bauman, 2008, p. 64). 
O mercado aquecido faz girar o círculo vicioso de produção e de consumo no qual o aumento do lucro das empresas permite maior empregabilidade, o que acarreta satisfação dos trabalhadores, empresários e governo (Benjamin, Marques \& Bessa, 2017). Tudo isso é contabilizado e personificado no PIB, principal índice de medida e comparação de progresso (Nalini, 2010).

Em correlação a tais argumentos, também é relevante a observação dos desdobramentos do "progresso" e da "modernidade", como fatores geradores do capitalismo moderno, como um modelo econômico de perpetuação e aprofundamento da miséria, alienação, desestruturação e da fome (Lutzenberger, 2012), bem como do descarte de produtos em geral e, especificamente os eletroeletrônicos. Nesse prisma crítico, a "cegueira seletiva" de empresas e governos também se perfaz na eleição de indicadores de análise do PIB, os quais não levam em consideração elementos fundamentais para a melhoria da qualidade de vida dos cidadãos (tais como: desigualdade de renda e danos ao meio ambiente), mas incluem outros fatores de amostragem como os índices de corrupção, de criminalidade e o consumo e tráfico de drogas e armas, como fatores capazes de incidir sobre o crescimento do PIB, podendo ser medidos como "riqueza" da nação (Lutzenberger, 2012). Ademais disto, se o crescimento econômico visualizado dentro do PIB não leva em conta os efeitos negativos deste progresso industrial, menos ainda são por ele consideradas as questões de ordem social (Benjamin, Marques \& Bessa, 2017).

Diante do consumismo desenfreado - que caracteriza uma parcela da filosofia comportamental da sociedade capitalista , Latouche (2012) constatou que, se todos vivessem como os franceses "seriam necessários três planetas, e seis para nos equipararmos aos nossos amigos americanos (sic)", para que se pudesse efetuar o descarte dos produtos e pontuou ainda que a sociedade encontra-se inserida em um consumo insustentável em que "a capacidade de regeneração da Terra não acompanha a procura: o homem transforma os seus recursos em lixo mais rapidamente do que a natureza pode transformar lixo em novos recursos" (Latouche, 2012, on-line).

No mesmo sentido, o Programa das Nações Unidas para o Meio Ambiente destacou que a produção de lixo eletrônico mundial cresce a uma taxa de 40 milhões de toneladas por ano (PNUMA, 2010) e estimou que, até o ano de 2020, o crescimento da produção de lixo eletrônico pode chegar a 500\% na Índia comparando a 2007 e a 400\% na China e na África do Sul.

Ao contextualizar o volume de produção de resíduos sólidos e alinhá-lo às consequências advindas da obsolescência planejada, passa-se a vislumbrar que tal questão não trata de um mero fenômeno de mercado e que seus efeitos não são inocentes, mas, ao contrário disto, são ferozes apesar de silenciosos (Nalini, 2010). Diz-se isso, pois ao inseri-la tanto no contexto econômico quanto no social, vislumbram-se finalidades diametralmente opostas fundadas no modelo capitalista e consumista vigente e o pretenso desenvolvimento sustentável; pois, enquanto o mercado não consegue enxergar em longo prazo e os economistas estão habituados a raciocinar em termos de anos, no máximo em décadas, a escala de tempo da ecologia se amplia para séculos e milênios (Sachs, 2002).

Isso porque, na outra ponta da engrenagem do consumo está o produto descartado a se acumular, o que tem tornado o "trabalho de limpeza" cada vez mais urgente, como bem observado por Bauman:

Novas necessidades exigem novas mercadorias, que por sua vez exigem novas necessidades e desejos; o advento do consumismo inaugura uma era de "obsolescência embutida" dos bens oferecidos no mercado e assinala um aumento espetacular na indústria da remoção do lixo (Bauman, 2008, p. 45).

Ao se levar em conta um mercado consumista que não pode parar, o crescimento vertiginoso de descarte de produtos e os altos custos que devem ser empregados para a aplicação das técnicas adequadas de reciclagem, têm-se o campo propício para um arranjo administrativo capaz de fazer escapar das empresas os custos que elas não estão dispostas a arcar, o que acaba por tornar o tráfico de lixo cada vez mais atrativo, como expõe Elisabeth Rosenthal: 
A exportação ilegal de lixo a países pobres é um negócio internacional crescente. As empresas tentam minimizar os custos de novas leis ambientais, como as da Holanda, que taxam o lixo e exigem que ele seja reciclado ou dispensado de forma ambientalmente correta. Roterdã, o porto mais movimentado da Europa, tornou-se o principal duto de escoamento de detritos da Europa para destinos como a América Latina. Nesses lugares, o lixo eletrônico e o entulho de construções contendo substâncias tóxicas costumam ser desmantelados por crianças, com grande prejuízo para sua saúde (Rosenthal apud Nalini, 2010, p. 349).

Para uma abordagem completa acerca da crise ambiental, devem ser considerados os aspectos políticos, econômicos e sociais da relação envolta do fenômeno da degradação ambiental (Latouche, 2012), mesmo quando inseridos no contexto do capitalismo verde, já que este é uma das facetas nas quais o próprio capitalismo se apresenta.

Desse modo, há de se atentar para o fato de as estratégias de financeirização da natureza (possíveis na bolsa de valores e dos hedge funds e fundos de investimento de risco), longe de evitar a degradação ambiental, tem servido apenas para a discussão de questões meramente técnicas e fundadas em fórmulas econômicas ou em avanços científicos (Sachs, 2002). Ao mesmo tempo em que a ausência do Estado forte tem conduzido às soluções ambientais para o campo da neutralização dos seus efeitos que são sentidos na expulsão de comunidades que vivem em florestas ou na proibição da pesca para os ribeirinhos diante de projetos de hidrelétricas, mineradoras (Lutzenberger, 2012).

O enfrentamento da crise ambiental, portanto, pode se voltar para uma solução que vislumbre mudanças no modo de vida e de produção e que integre vertentes tecnológicas, econômicas e políticas, de tal modo que esta se mostra como a proposição mais adequada diante dos acordos econômico-ambientais firmados a partir da década de 1980, tratando do tema, quando estes tão somente fundam meras “declarações de intenções” e não as necessárias medidas concretas (Milaré, 2011).

Todavia, os efeitos declaratórios não reduzem a importância destes acordos quando, por essência, estão fixados os entendimentos de que tais documentos funcionam como "bússolas" para perspectivas interdisciplinares (tais como a mobilidade das cidades, trabalho infantil, redução do aquecimento global) (Léna \& Nascimento, 2012), garantindo estruturas capazes de produzir vários mecanismos de soluções para questões específicas, ao invés de uma única grande solução.

A Justiça distributiva, inserta no contexto ambiental, pode ser percebida como a distribuição equitativa dos riscos, impactos e benefícios tecnológicos e ambientais de uma sociedade, compreendendo: a poluição do ar, aterros, fábricas industriais e outros encargos ambientais. A justiça distributiva é um princípio essencial da justiça ambiental, porque há evidências de que esses encargos causam problemas de saúde, afetam negativamente a qualidade de vida e reduzem o valor da propriedade (Nalini, 2010; Milaré, 2011; Lutzenberger, 2012).

Nesse prisma, é possível perceber a necessidade da aplicação de uma justiça distributiva para o acertamento da responsabilização pelo descarte correto do lixo, decorrente da conduta empreendida por consumidores guiados pela efemeridade expressa na caracterização da vida útil reduzida do produto em razão da necessidade de sua substituição (Benjamin; Marques; Bessa, 2017). Ao não se pautarem novos modelos para a solução do descarte de produtos tecnológicos, estarão os mercados e as economias mais fortes a imporem seus estilos de vida sob um custo que será pago pelos países mais pobres, como os africanos (Latouche, 2012), que tem sido o principal destino dado ao lixo residual eletroeletrônico, cabendo a eles pagar pelos os custos ambientais dos países desenvolvidos e em desenvolvimento.

Sob essas perspectivas é que as insustentáveis tendências de consumo necessitam ser alvo de profundas mudanças nos estilos de vida da maior parte das pessoas e dos países de maior desenvolvimento, diante da adoção de novos padrões de consumo e de produção, de modo a diminuir a tensão causada pelo apelo consumista, o que reforça o emprego do capitalismo verde e da justiça distributiva tanto no início da relação de consumo quanto no final desta relação fixada no descarte. 


\section{Considerações Finais}

O consumo ostensivo, principalmente de produtos tecnológicos, apresenta impactos ambientais e de matrizes socioeconômicas desiguais, que erguem na sociedade contemporânea danos causados pelo descarte mal planejado de resíduos, cuja transferência internacional pode vir a implicar a outras nações os efeitos de possíveis danos já dimensionados, mas sem indicadores de redução (ONU, 2005).

Assim sendo, as informações levantadas no presente estudo buscaram compreender o arcabouço normativo, doutrinário e de indicadores econômicos, situando o descarte de resíduos eletroeletrônicos como uma realidade periclitante para o meio ambiente, cujos indicadores têm demonstrado a previsão de contínuo aumento para as décadas seguintes, com base no marketing voltado para o consumo de produtos e tecnologias desenvolvidos e atualizados também de maneira programada, visando a diferenciação social baseada no poder aquisitivo.

Portanto, a produção da esperada equidade social (Dworkin, 2006), pautada na responsabilização de atos lastreados à proporcionalidade do consumo entre indivíduos mais e/ou menos afortunados (Rawls, 1997), é capaz de compreender que os efeitos transbordam o consumidor direito e atingem indivíduos outros de maneira indireta, numa relação não optativa, causada por variados agentes poluentes, mas especialmente e a longo prazo, os resíduos eletroeletrônicos, os quais mitigam a efetiva fruição do direto às cidades (Lefebvre, 2001), deterioram e contaminam locais de depósito final e aprofundam abismos socioeconômicos e geopolíticos, criando realidades cada vez mais equidistantes entre Estados e populações.

De modo complementar aos esforços já realizados até a atualidade, é possível vislumbrar perspectivas e iniciativas capazes de garantir maior equidade na disponibilização e nas garantias de acesso a bens de consumo e serviços, desde a produção até o descarte, garantindo maior igualdade a consumidores em produtos ecologicamente melhor desenvolvidos. Logo, é possível elencar os avanços científicos, a reestruturação do setor industrial, o aperfeiçoamento de legislações, novos tratados e convênios e campanhas de conscientização voltadas para a população, como estratégias de reeducação e reformulação das práticas consumistas culturais.

Todavia, somente tais ações não podem ser tidas como suficientes para a preservação do meio ambiente e da manutenção da vida da vida das espécies atingidas pela poluição eletroeletrônica, caso não ocorram ajustes e melhorias nos valores e posturas dos consumidores, dos órgãos públicos e das empresas privadas. Isso posto, a responsabilidade deve alcançar uma relação global, em que as decisões tomadas pelos governos nacionais tenham uma visão prospectiva, dentro de uma atuação pautada na presença absoluta do Estado (e não de governo) e em seu agir consciente, para a promoção da sociedade e a regulação da distribuição de riquezas com justiça.

Sob tais perspectivas, ao partir de uma escala micro para uma escala macroeconômica, assumindo indicadores em nível mundial, a pesquisa realizada também apontou para a ausência de enfrentamento do consumismo, voltado especialmente para produtos tecnológicos que já nascem com durabilidade e vida útil programadas, o que evidenciou a necessidade de promover discussões globalizadas quanto às individualizações de responsabilidades decorrentes de danos transindividuais coletivos, difusos e ambientais, que atingem a vida e à dignidade de populações (vegetais e animais, incluindo a humana) a coexistirem em um ambiente sadio.

Outro desafio está na construção de um consumo sustentável que, além de pressupor a reciclagem e a reutilização dos resíduos da produção, leve em conta a satisfação pessoal e os efeitos ambientais e sociais das gerações vindouras, sendo tais parâmetros objeto de práticas educacionais que enfatizem a forma consciente de viver e fomentem a satisfação das necessidades fundamentais com o menor desperdício. As mudanças necessárias devem ser capazes de criar mecanismos mais eficazes para promoção da preservação ambiental e do consumo, pelas vias legislativas, sociais, filosóficas, econômicas e políticas, objetivando uma transformação profunda de comportamentos e ampliando o senso de responsabilidades individuais e coletivas 
quanto às formas de produção atreladas ao Capitalismo Verde e o planejamento científico do descarte de produtos de difícil decomposição em ambiente natural.

As dimensões alcançadas pelos princípios distributivos justos podem (e deveriam) estar inseridas nos mecanismos de produção que utilizam os paradigmas propostos no capitalismo verde, visando à responsabilidade ambiental em todas as etapas do consumo mais especialmente, na fase de descarte, quando o ciclo econômico não se encontra totalmente encerrado, pois continua produzindo impactos de desvalorização ambiental, econômica e da vida, em perspectiva local e também mundial. O direito à cidade também pode (e deveria) ser reconhecido como uma virtude comunitária de aspecto intergeracional comum e não apenas como uma escolha entre a permanência de leis de gestão, políticas de governos ou métodos produtivos voltados para o lucro imediato de empresas privadas, visando expandir a democracia da forma de governo, para ema virtude social e ambiental capaz de reduzir desigualdades. Afinal, a grande parcela dos seres vivos do planeta Terra e o meio ambiente, em suas mais variadas expressões, nada lucram e não deveriam custear - com o seu padecimento e a sua falta de consentimento, a crença de que o resultado para alguns, vale o alto custo para todos.

\section{Referências}

Acselrad, H. (org.). (2004). Conflitos ambientais no Brasil. Relu-me Dumará, Fundação Heinrich Böll.

Aragão, M. A. S. (2003). O direito dos resíduos. Almedina.

Araújo, N. (2011). Direito internacional privado: teoria e prática brasileira. (5a ed.), atualizada e ampliada. Renovar.

Assembleia Geral das Nações Unidas (1985). Resolução 44/228. Assembleia Geral. <https://www.un.org/documents/ga/res/44/ares44-228.htm>.

Baldé, C.P., Forti V., Gray, V., Kuehr, R., \& Stegmann, P. (2017). The Global E-waste Monitor - 2017.United Nations University (UNU), International Telecommunication Union (ITU) \& International Solid Waste Association (ISWA), Bonn/Geneva/Vienna. <https://www.itu.int/en/ITU-D/ClimateChange/Documents/GEM\%202017/Global-E-waste\%20Monitor\%202017\%20.pdf>.

Baudrillard, J. (2003). A sociedade de consumo. Edições 70.

Bauman, Z. (2008). Vida para consumo: a transformação das pessoas em mercadoria. Zahar.

Brasil. (2018). Constituição de 1988. Constituição da República Federativa do Brasil. (53a ed.), Câmara dos Deputados: Edições Câmara.

Brasil. (1997). Lei $n^{\circ}$ 9.433, de 08 de janeiro de 1997 - Lei de Política de Recursos Hídricos. Brasília: Diário Oficial da União - DOU, de 09 jan. 1997. <http://www.planalto.gov.br/ccivil_03/Leis/L9433.htm>.

Brasil. (1999). Lei $n^{o}$ 9.795, de 27 de abril de 1999. Brasília: Diário Oficial da União - DOU, de 28 abr. 1999. <http://www.planalto.gov.br/ccivil_03/leis/19795.htm>.

Brasil. (2001). Lei $n^{o}$ 10.257, de 10 de julho de 2001. Brasília: Diário Oficial da União - DOU, de 17 jul. 2001. Recuperado de: < http://www.planalto.gov.br/ccivil_03/leis/leis_2001/110257.htm>

Brasil. (2010). Lei 12.305, de 02 de agosto de 2010 - Lei da Política Nacional de Resíduos Sólidos. Brasília: Diário Oficial da União - DOU, de 03 ago. 2010. <http://www.planalto.gov.br/ccivil_03/_ato2007-2010/2010/lei/112305.htm>.

Brasil. (2012). Lei $n^{o}$ 12.651, de 12 de maio de 2012 - Código Florestal. Brasília: Diário Oficial da União, de 25 maio 2012. <http://www.planalto.gov.br/ccivil_03/_Ato2011-2014/2012/Lei/L12651.htm>.

Beck, U. (2011). Sociedade de Risco: rumo a uma outra modernidade. (2a ed.), Editora 34.

Benjamin, A. H. V. (1998). Responsabilidade civil pelo dano ambiental. Revista de Direito Ambiental. n 9.

Benjamin, A. H. V., Marques, C. L. \& Bessa, L. R. (2017). Manual de Direito do Consumidor. (8a ed.), Revista dos Tribunais.

Comissão Mundial sobre Meio Ambiente e Desenvolvimento. (1992). Nosso futuro comum. (2a ed.), Editora da Fundação Getúlio Vargas.

Conceição, M. M., Conceição, J. T. P. \& Araujo, P. S. L. A. (2014). Obsolescência programada - tecnologia a serviço do capital. In: INOVAE - Journal of Engineering and Technology Innovation. São Paulo. 2 (1), 90-105.

Costa, J. F. (2004). O vestígio e a aura: corpo e consumismo na moral do espetáculo. Garamond.

Dworkin, R. (2006). Justice in Robes. Harvard University Press.

Elkington, J. (2001). Canibais com Garfo e Faca. Makron Books. 
Flores, M. P., Araujo, L. E. B. \& Tybusch, J. S. (2013) Sustentabilidade, Globalização Econômica e a Ascensão do Capitalismo Verde. Revista Eletrônica do Curso de Direito - UFSM, 8. <Https://periodicos.ufsm.brrevistadireito/article/view/8411>.

Fromm, E. (2008). Ter ou ser. (4a ed.), Livros Técnicos e Científicos - LTC.

Hobbes, T. (2003). Leviatã ou matéria forma e poder de um Estado eclesiástico e civil. Tradução João Paulo Monteiro e Maria Nizza da Silva. São Paulo: Martins Fontes.

Hock, W. (1960). Deutscher Antikapitalismus. Der ideologische Kampf gegen die freie Wirtschaft im Zeichen der großen Krise. Frankfurt am Main: Fritz Knapp Verlag.

Josserand, L. (1941). Evolução da responsabilidade civil. Trad. Raul Lima. Revista Forense, (86), 548-559.

Latouche, S. (2012). O pequeno tratado do decrescimento sereno. Edições 70.

Latour, B. (2004). Políticas da natureza: como fazer ciência na democracia. Tradução de Carlos Aurélio Mota de Souza. Edusc.

Lefebvre, H. (2001). O Direito à cidade. Tradução de Rubens Eduardo Frias, São Paulo: Centauro. <https://monoskop.org/images/f/fc/L efebvre_Henri_O_direito_a_cidade.pdf>.

Lena, P. \& Nascimento, E. P. (2012). Enfrentando os limites do crescimento: sustentabilidade, decrescimento e prosperidade. Garamond.

Locke, J. (1973). Coleção Os Pensadores John Locke. Abril Cultual.

Lutzenberger, J. A. (2012). Crítica ecológica do pensamento econômico. L\&PM.

Madeira Filho, W. \& Simon, A. (2016). Tecnologia e conflito socioambientais: o difícil percurso para a consolidação de uma epistemologia ambiental. Em: CARLI, Ana Alice de, SANTOS, Fabiana Soares dos, SEIXAS, Marcus Wagner de. A tecnologia em prol do meio ambiente: a partir de uma análise multidisciplinar. Lumen Juris, p. 215-228.

Marx, K., \& Engels, F. (1948). Manifesto of the Communist Party. https://www.marxists.org/archive/marx/works/download/pdf/Manifesto.pdf.

Milaré, É. (2011). Direito do Ambiente: a gestão ambiental em foco. Revista dos Tribunais.

Nações Unidas do Brasil. (2018). A ONU e o Meio Ambiente. 〈http://www.onu.org.br/a-onu-em-acao/a-onu-e-o-meio-ambiente>

Nalini, J. R. (2010). Ética Ambiental. Millennium Editora.

Nascimento, I. P. (2002). As representações sociais do projeto de vida dos adolescentes: um estudo psicossocial. 380 f. Tese (Doutorado em Educação) Programa de Pós-Graduação em Psicologia da Educação, Pontifícia Universidade Católica de São Paulo, São Paulo.

Nozick, R. (1974). Anarchy, state and utopia. Basic Books.

Organização das Nações Unidas. (2005). Avaliação Ecossistêmica do Milênio. New York: ONU. $<$ http://www.millenniumassessment.org/documents/document.446.aspx.pdf>.

Parlamento Europeu. (2012). Conselho da União Europeia. Diretiva 2012/19/UE Do Parlamento Europeu e do Conselho, de 4 de julho de 2012 relativa aos resíduos de equipamentos elétricos e eletrônicos (REEE). Estrasburgo: Jornal Oficial da União Europeia, de 24 jul. p. 38-71. <https://eur-lex.europa.eu/legalcontent/PT/TXT/PDF/?uri=CELEX:32012L0019\&from=EN>.

Pereira A.S. et al. (2018). Metodologia da pesquisa científica. UFSM. https://repositorio.ufsm.br/bitstream/handle/1/15824/Lic_Computacao_MetodologiaPesquisa-Cientifica.pdf?sequence=1.

Pereira, C. M. S. (1999). Responsabilidade civil. (9a ed.), Forense.

Pereira, C. M. S. (2001). Direito civil: alguns aspectos da sua evolução. Forense.

Perlingeiro, R. (2014). Eficácia da jurisdição externa. Eduff.

Polakovic, G. (2002). O homem consome e a Terra não consegue repor. O Estado de S. Paulo. Geral/Ambiente.

Programa das Nações Unidas para o Meio Ambiente - PNUMA. (2011). Caminhos para o Desenvolvimento Sustentável e a Erradicação da Pobreza - Síntese para Tomadores de Decisão. Brasília: PNUMA. 〈http://www.fapesp.br/rio20/media/Rumo-a-uma-Economia-Verde.pdf >

Rawls, J. (1997). Uma teoria da Justiça. Martins Fontes.

Retondar, A. M. (2007) Sociedade de Consumo, Modernidade e Globalização. Annablume, EDUFCG.

Sachs, I. (2002). Caminhos para o Desenvolvimento Sustentável. (2a ed.), Garamond. 